\title{
Cell-free nucleic acids as noninvasive biomarkers for colorectal cancer detection
}

\author{
Hicham Mansour* \\ Biosciences Core Laboratories, Research Department, King Abdullah University of Science and Technology, Thuwal, Kingdom of Saudi Arabia
}

\section{Edited by:}

Rajib Bandopadhyay, Birla Institute

of Technology, India

Reviewed by:

Bertrand Tan, Chang Gung

University, Taiwan

Milind Ratnaparkhe, Directorate of

Soybean Research, India

*Correspondence:

Hicham Mansour, Biosciences Core Laboratories, Research Department, King Abdullah University of Science and Technology, Building 2, Thuwal 23955-6900, Kingdom of Saudi

Arabia

e-mail:hicham.mansour@

kaust.edu.sa;

mansour.hicham@gmail.com
Cell-free nucleic acids (CFNA) have been reported by several authors in blood, stool, and urine of patients with colorectal cancer (CRC). These genetic biomarkers can be an indication of neoplastic colorectal epithelial cells, and can thus potentially be used as noninvasive tests for the detection of the disease in CRC patients and monitor their staging, without the need to use heavier and invasive tools. In a number of test-trials, these genetic tests have shown the advantage of non-invasiveness, making them well accepted by most of the patients, without major side effects. They have also shown a promising sensitivity and specificity in the detection of malignant and premalignant neoplasms. Moreover, costs for performing such tests are very low. Several studies reported and confirmed the proof of the principle for these genetic tests for screening, diagnosis, and prognosis; the main challenge of translating this approach from research to clinical laboratory is the validation from large and long-term randomized trials to prove sustainable high sensitivity and specificity. In this paper, we present a review on the noninvasive genetics biomarkers for CRC detection described in the literature and the challenges that can be encountered for validation processes.

Keywords: colorectal cancer, cell-free nucleic acids, CFNA, biomarkers, noninvasive tests, miRNAs, DNA mutation, DNA methylation

\section{INTRODUCTION}

Colorectal cancer (CRC) is the most common cancer worldwide, and it is the second cause of cancer death just behind lung cancer (Ferlay et al., 2010). Recent data collected by Globocan, show an estimated 1.3 million new CRC cases during 2012, 693,881 resulting in death (http://globocan.iarc.fr/Pages/online. aspx). The CRC incidence and mortality are actually increasing despite recent advances in surgery, radiotherapy and chemotherapy (Boyle and Langman, 2000). Tumor progression of CRC is governed by either genetic or epigenetic changes intrinsic to neoplastic colorectal epithelial cells. CRC can be caused by changes in different molecular pathogenic pathways, such as chromosomal instability, $\mathrm{CpG}$ island methylator phenotype, and microsatellite instability. The majority of the cases are sporadic (not inherited). Sporadic changes may be acquired from diverse factors such as environmental exposures, diet, hormones, and normal aging. There are also cases of inherited CRC, the most known hereditary CRC being Familial adenomatous polyposis (FAP), Hereditary nonpolyposis colorectal cancer (HNPCC), Autosomal recessive adenomatous polyposis, and Oligodontia-colorectal cancer syndrome (Haggar and Boushey, 2009; Schweiger et al., 2013). Mutations in a single gene such as APC, MSH2, MLH1, PMS1, PMS2, MSH6, TGFBR2, MLH3, MUTYH, and AXIN2 result in a marked predisposition to mentioned hereditary CRC (Schweiger et al., 2013).

In most cases, the natural history of CRC follows a progression from benign polyps to advanced CRC, this process often spanning several years. Tumor detection at early disease stages together with monitoring of disease progression toward malignancy, have shown a reduction in mortality rates (Scholefield et al., 2012; Shaukat et al., 2013). Thereby, tumor control leads to better care of affected patients. Colonoscopy is currently the standard approach to tumor diagnosis, with a relatively high cost and recognized invasiveness with the potential for serious complications. Practical limitations restrict the use of colonoscopy for screening. An alternative method, Fecal Occult Blood Testing (FOBT) has been widely used to detect blood in fecal samples. The FOBT employs the pseudoperoxidase activity of hemoglobin's heme moiety in blood containing samples. More recently, the use of an immunological reaction directed to detect hemoglobin via heme-specific antibody has served as an alternative to the enzyme detection method. Unfortunately, several trials have shown the occurrence of a high rate of false-negatives and positives for these tests (Imperiale et al., 2004; Ebert et al., 2006; Bin Raies et al., 2013; Mansour et al., 2013; Roperch et al., 2013), Therefore, the need to develop an effective noninvasive assay to screen patients for CRC at early stages remains urgent.

\section{CFNA MARKERS IN BODY FLUIDS OUTLOOK}

Since the first discovery in 1948 by Mandel of the occurrence of CFNA in blood (Mandel and Metais, 1948), researchers have found nucleic acids in body fluids that track and discriminate affected patients from healthy subjects. In the cancer field, researchers have also found traces of shed tumoral-nucleic acids in different biological effluents such as stool, blood, and urine. 
The recognition of the advantages and the proof-of-concept of using CFNAs for noninvasive cancer detection naturally followed their discovery (Imperiale et al., 2004; Muller et al., 2004; Ebert et al., 2006; Mansour and Sobhani, 2009; Roperch et al., 2013).

\section{SELECTION OF LITERATURE}

We performed a literature search to capture identified tumorrelated CFNAs reported to distinguish CRC patients from healthy subjects. Thereby, a search from the NCBI Entrez search line selected to the PubMed index was performed with the following string: (plasma OR serum OR stool OR urine OR blood OR body fluids) AND (colorectal cancer OR colorectal neoplasms OR colorectal neoplasm OR colon cancer OR rectal cancer) AND (mutation or methylation or microRNA OR transcript OR mRNA OR miR OR RNA). The search yielded 3674 entries. The addition of the term "noninvasive" to the search string reduced the number of resulting titles to 109 . The output data identified by these later inclusion criteria are reviewed and summarized in Table 1.

\section{LITERATURE SEARCH RESULTS}

This section is organized as follows: We first describe the different available molecular approaches for the detection of anomalies in CFNA in body fluids, we then review the inclusion criteria for the patient cohorts and we finally describe the known CFNA biomarkers.

\section{Molecular approaches}

Several molecular approaches are used to detect the CFNA in the body fluids of CRC patients and to quantify the molecular anomalies that could reveal neoplastic traces. The quantitative polymerase chain reaction (QPCR or RT-PCR) is widely used. Other tools are also reported such as DNA Beaming Technology, Methylation Array, DNA array, Surface-Enhanced Raman Scattering (SERS), and Restriction Fragment Length Polymorphism (RFLP). While most of these methods capture and enrich the tumoral nucleic acids to bring their levels to the detection and quantification thresholds, the sensitivity of these instruments, and techniques vary considerably with a resulting influence on the performance of the test to distinguish the cancer from the normal. This variability was observed even when evaluating the same marker. One new molecular approach for evaluation the whole CFNA that can be found in the body fluids is the use of next generation sequencing (NGS), as in Leary et al. (2012). They scanned the whole genome of plasmatic DNA to detect which composites of chromosomal structure variations present in CRC tumorigenesis could discriminate between CRC patients and healthy subjects. Promising results were found discriminating CRC patients at advanced stage from healthy controls, but these results would benefit from a more in-depth study on a large cohort and at earlier disease stages. This study did emphasize the value of using NGS to CRC detection. NGS applied to CRC detection could provide high sensitivity through high sequencing coverage and selectivity through complete analysis of high quality data.

\section{Patients}

In term of patients' inclusion and tumor criteria, the majority of these studies used average-risk population. Different tumor sizes were considered: small adenomas, adenomas having more than $1 \mathrm{~cm}$ in size and carcinomas at different stages (I, II, III, or IV). The cancer locations were mainly ascending colon, transverse colon, descending colon, sigmoid colon, and rectum. Three clinical trials differed strongly from all the others. The first one was a study from Manenti et al. (Villa et al., 1996), focusing on Kras gene mutations in the stool of 230 consecutive patients. The consecutive patient selection strategy gives unbiased sensitivity and specificity regarding the test used and clearly aims to avoid bias possibly introduced by patient selection. The two others outstanding studies were performed by Imperiale et al. They evaluated 21 mutations in APC, Kras, and P53 genes on asymptomatic subjects $(n=4404)$ tested already for FOBT (Imperiale et al., 2004), and they recently evaluated KRAS mutations, aberrant NDRG4 and BMP3 methylation, and $\beta$-actin on very large number of individuals $(n=9989)$ tested for FIT (Imperiale et al., 2014). Inclusion of a very large number of asymptomatic subjects shows the potential of sensitivity gain for molecular testing (Imperiale et al., 2004, 2014). With these inclusion criteria, the authors simulated a real situation of screening and applied powerful statistical tools to evaluate the true performance of the test used. Globally, the authors claim a higher sensitivity for the multitarget stool DNA testing over the two tests FOBT and the FIT, but had more false positives results (Imperiale et al., 2004, 2014). Other authors have identified, albeit in small cohorts, several others combinations of useful biomarkers. Studies directed at larger cohorts are awaited to provide confidence on the performance of the composite panels that were chosen for these studies.

\section{Biomarkers}

The first results to provide a conceptual framework and a practical basis for a new molecular approach to detect the presence of genetic anomalies in CFNAs isolated from CRC patient stool samples were published in 1992 by Bert Vogelstein et al. (Sidransky et al., 1992). In this work, the authors were able in a relatively easy manner, to detect $\mathrm{K}$-ras gene mutations in patients with CRC. They successfully detected Kras mutation in $89 \%$ of the patients. Since this first published results targeting Kras, other anomalies were measured directly from CFNAs including deletions, microsatellite instability, loss of heterozygosity, copy number variation, chromosomal rearrangements, DNA, and microRNA methylation changes and mis-expression of mRNAs and microRNAs. Many genes have been shown affected in CRC, are involved in various critical signaling molecular pathways, but their diagnostic usefulness and specificity vary considerably. Here follows a description of the most common CFNA biomarkers, subdivided by subclasses, namely mutation, methylation, and microRNA.

\section{MUTATION BIOMARKERS KRAS}

Kras, a Kirsten ras oncogene, encodes a protein that is a member of the small GTPase superfamily. The protein is involved in many vital signaling pathways, including proliferation, differentiation, and senescence. A single amino acid substitution is responsible for an activating mutation. The transforming protein that results 
Table 1 | Summary of genetic markers found in body fluids from CRC patients.

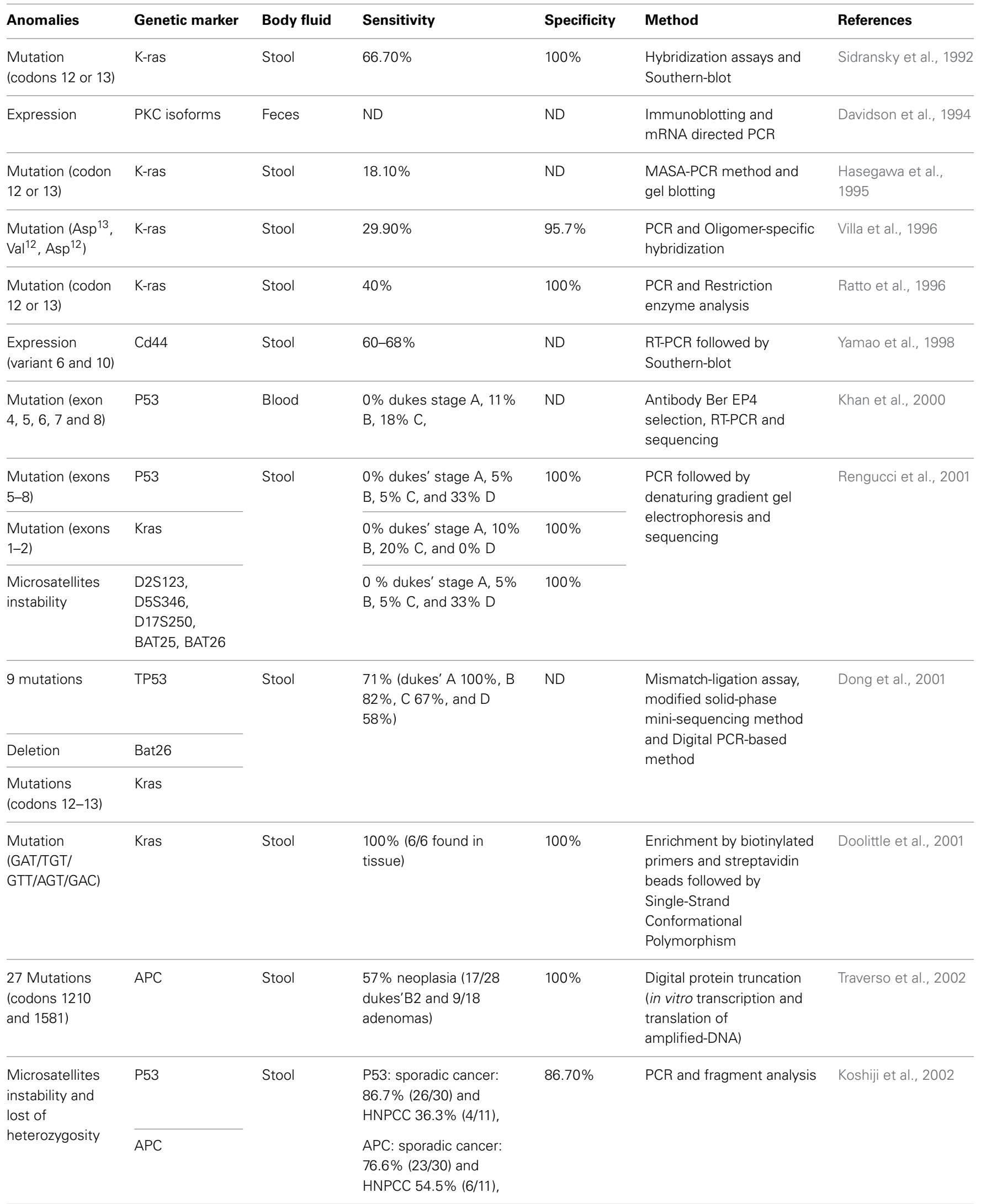


Table 1 | Continued

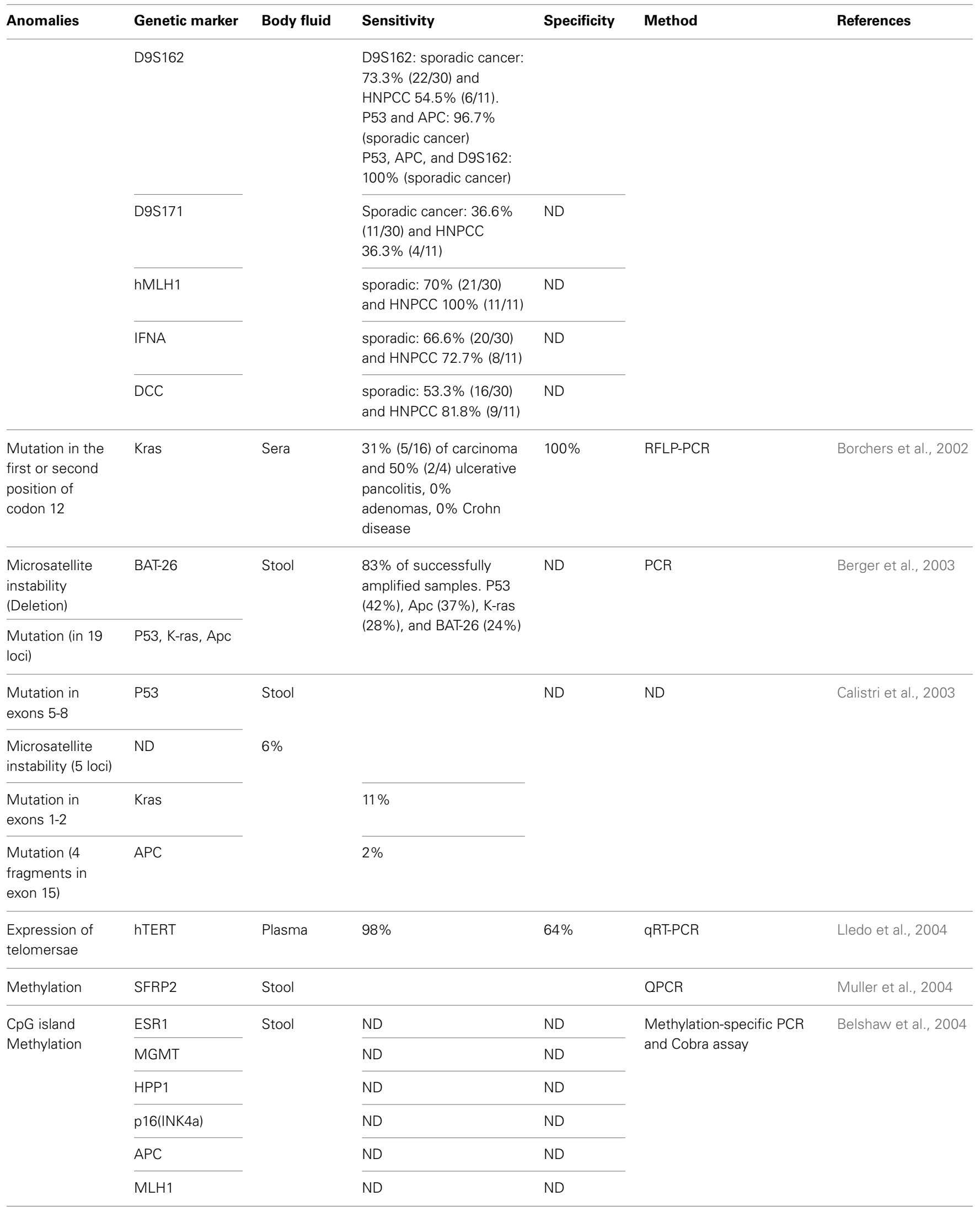


Table 1 | Continued

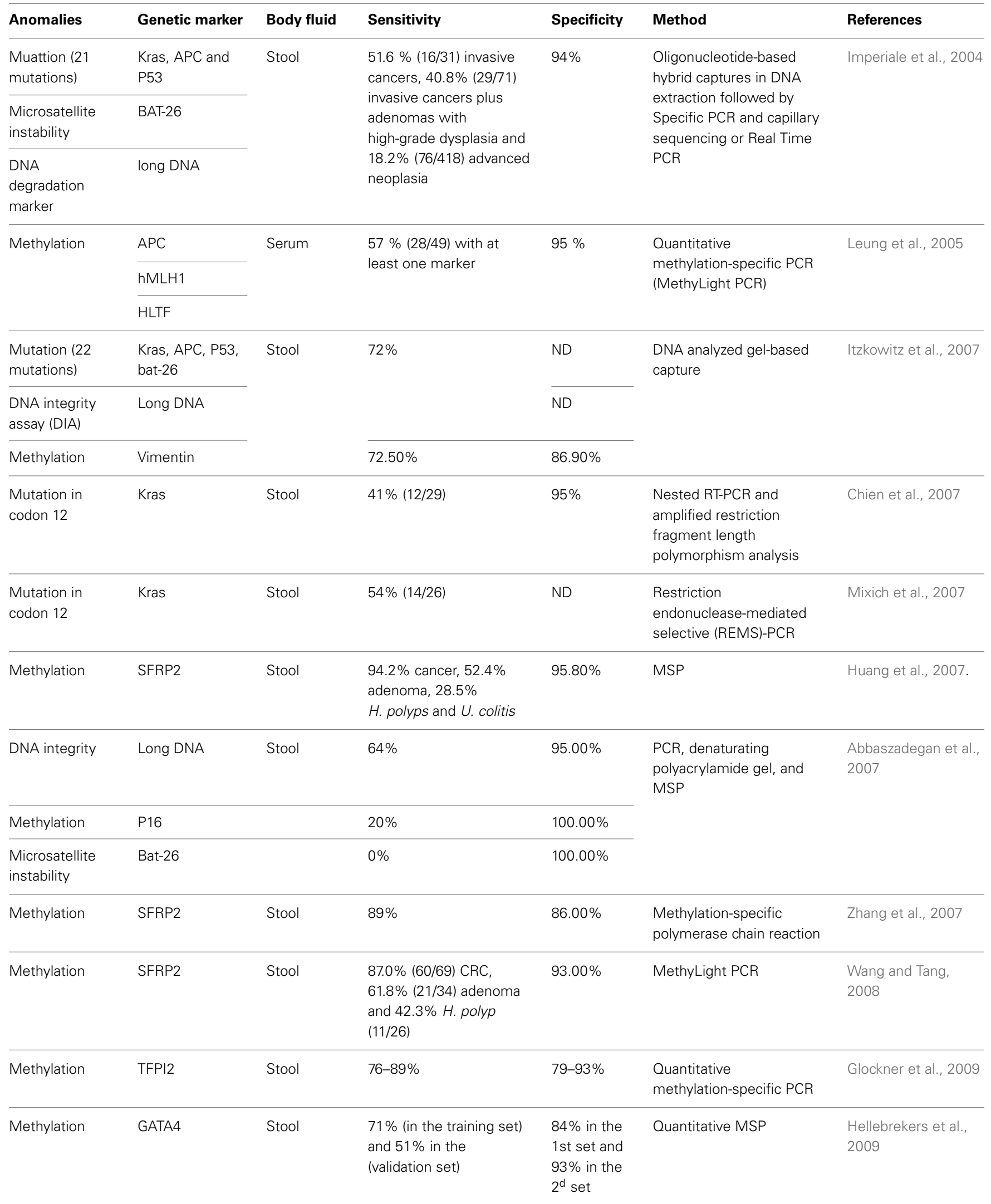


Table 1 | Continued

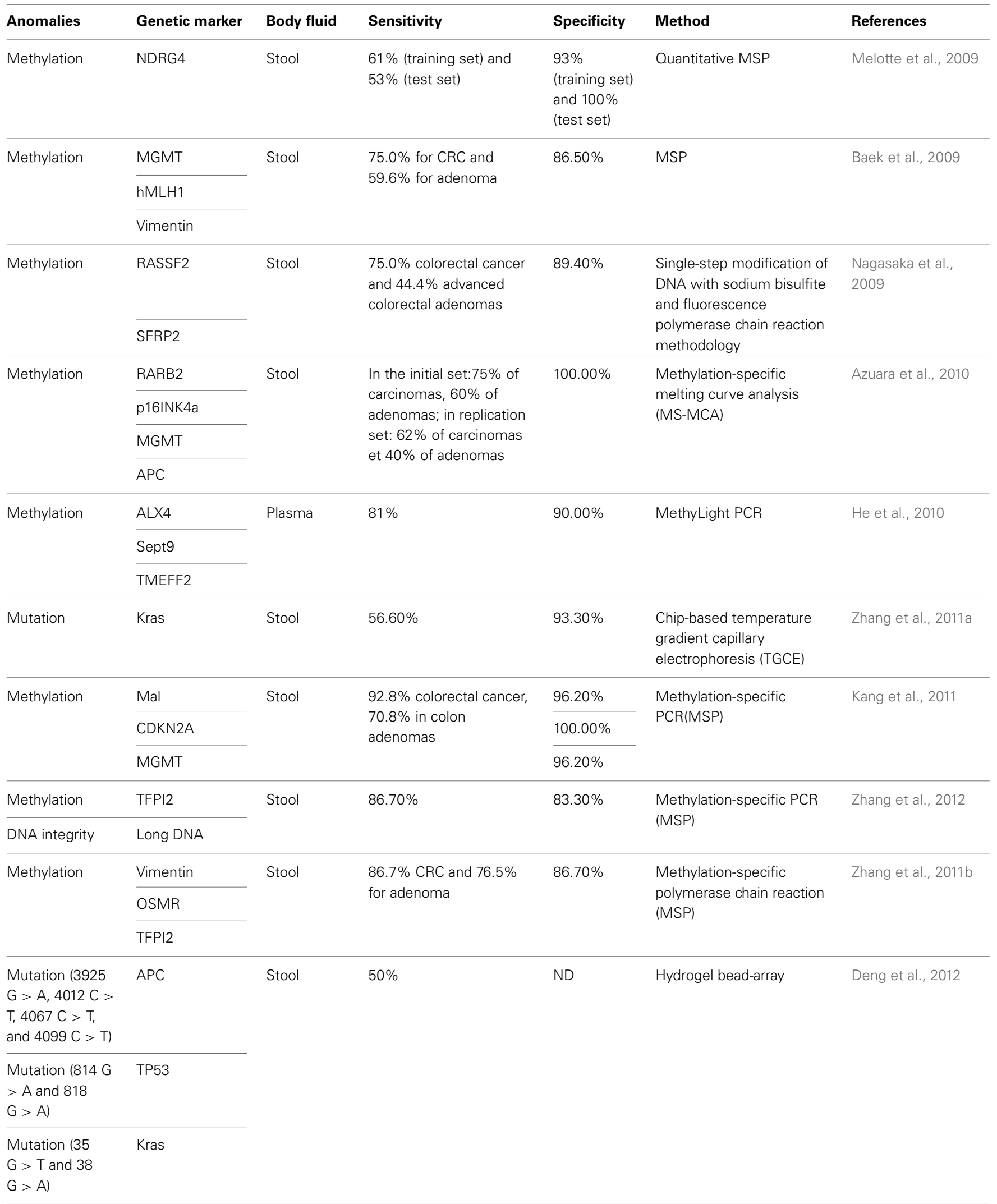


Table 1 | Continued

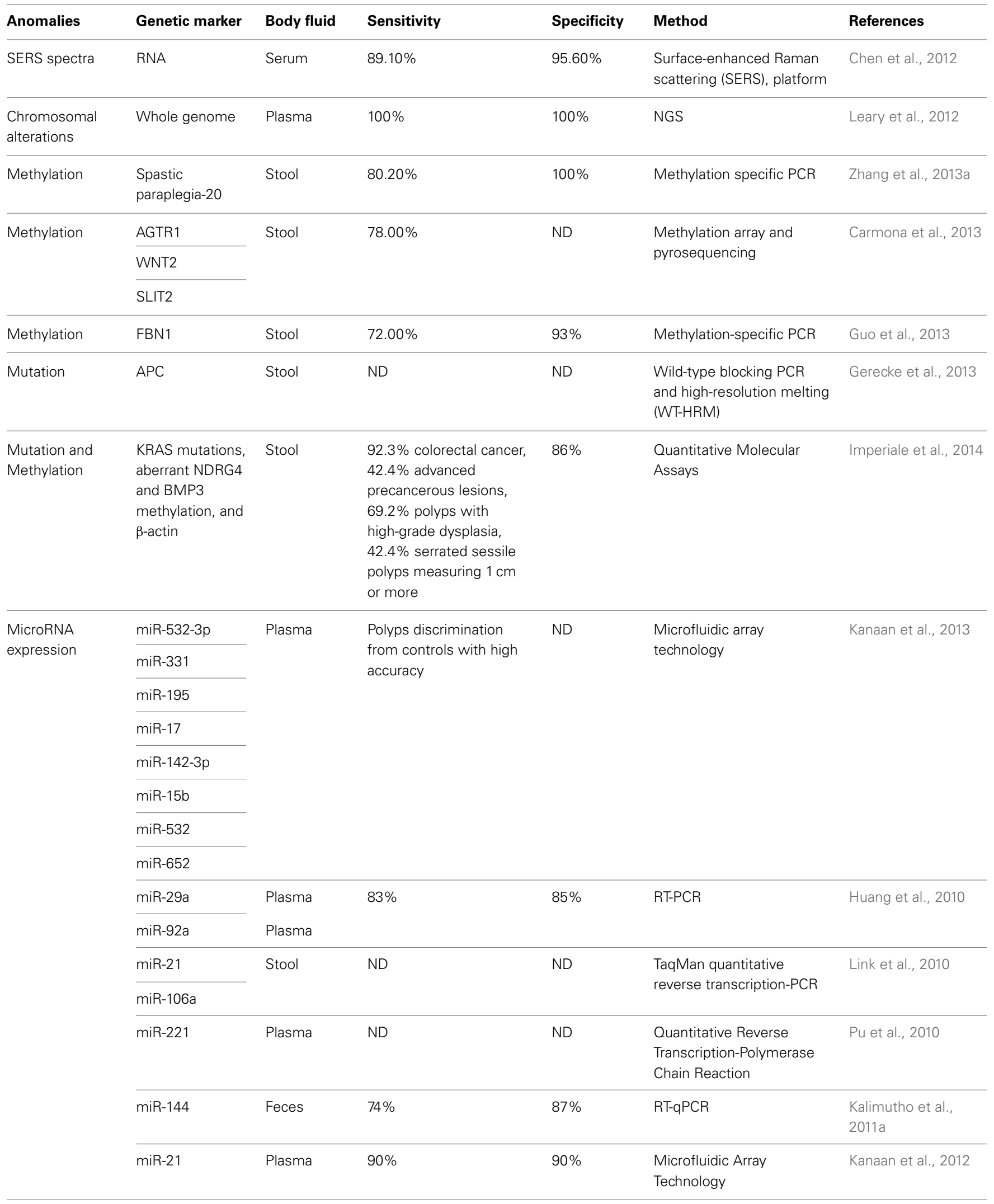


Table 1 | Continued

\begin{tabular}{|c|c|c|c|c|c|c|}
\hline Anomalies & Genetic marker & Body fluid & Sensitivity & Specificity & Method & References \\
\hline & $\operatorname{miR}-135 b$ & Plasma & $\begin{array}{l}78 \% \text { for } \mathrm{CRC}, 73 \% \text { for } \\
\text { advanced adenoma, and } \\
65 \% \text { for any adenoma }\end{array}$ & $68 \%$ & microRNA expression array & Wu et al., 2014b \\
\hline & miR-18a & Plasma & ND & ND & $\begin{array}{l}\text { Microfluidic Array } \\
\text { Technology }\end{array}$ & Komatsu et al., 2014 \\
\hline & miR-92 & Plasma & $89 \%$ & $70 \%$ & Real-Time PCR & Ng et al., 2009 \\
\hline & miR-141 & Plasma & ND & ND & $\begin{array}{l}\text { Quantitative Reverse } \\
\text { Transcription-Polymerase } \\
\text { Chain Reaction }\end{array}$ & Cheng et al., 2011 \\
\hline & miR-378 & Plasma & ND & ND & $\begin{array}{l}\text { Quantitative Real Time } \\
\text { PCR }\end{array}$ & Zanutto et al., 2014 \\
\hline & miR-200c & Plasma & $84.60 \%$ & $75.60 \%$ & ND & Zhang et al., 2013b \\
\hline & miR-18a & & & & & \\
\hline & $\begin{array}{l}\text { RNU2-1f } \\
\text { (Circulating U2 } \\
\text { small nuclear } \\
\text { RNA) }\end{array}$ & Plasma & $98 \%$ & $91 \%$ & qRT-PCR & $\begin{array}{l}\text { Baraniskin et al., } \\
2013\end{array}$ \\
\hline & $\begin{array}{l}\text { let-7a, miR-1229, } \\
\text { miR-1246, } \\
\text { miR-150, } \\
\text { miR-21, } \\
\text { miR-223, and } \\
\text { miR-23a }\end{array}$ & Serum & ND & ND & $\begin{array}{l}\text { Microarray analyses and } \\
\text { Real Time PCR }\end{array}$ & $\begin{array}{l}\text { Ogata-Kawata et al., } \\
2014\end{array}$ \\
\hline
\end{tabular}


Table 1 | Continued

\begin{tabular}{|c|c|c|c|c|c|c|}
\hline Anomalies & Genetic marker & Body fluid & Sensitivity & Specificity & Method & References \\
\hline & miR19a & Plasma & $80.95 \%$ for TNM I/II, & $79.25-$ & & Giraldez et al., 2013 \\
\hline & miR19b & & 76.19\% for TNM III/IV & $77.36 \%$ & $\begin{array}{l}\text { expression profiling assay } \\
\text { and qRT-PCR }\end{array}$ & \\
\hline & $\operatorname{miR} 15 b$ & & & & & \\
\hline & miR-21 & Serum & $90 \%$ & $90 \%$ & $\begin{array}{l}\text { Microfluidic array } \\
\text { technology }\end{array}$ & Kanaan et al., 2012 \\
\hline & miR-29a & Plasma & $83 \%$ for $\mathrm{CRC}$ and $73 \%$ & $84.7 \%-$ & Real Time PCR & Huang et al., 2010 \\
\hline & miR-92a & & for advanced adenomas & $79.7 \%$ & & \\
\hline & miR-21 & Stool & Higher expression & ND & Taqman-RT-PCR & Link et al., 2010 \\
\hline & miR-106a & & & & & \\
\hline & miR-144 & Stool & $74 \%$ & $87 \%$ & RT-pre-amplification-qPCR & $\begin{array}{l}\text { Kalimutho et al., } \\
\text { 2011a }\end{array}$ \\
\hline & miR-221 & Plasma & $86 \%$ & $41 \%$ & $\begin{array}{l}\text { Quantitative Reverse } \\
\text { Transcription-Polymerase } \\
\text { Chain Reaction without } \\
\text { RNA extraction }\end{array}$ & Pu et al., 2010 \\
\hline \multirow{5}{*}{$\begin{array}{l}\text { MicroRNA } \\
\text { Methylation }\end{array}$} & miR-34a & Stool & $77 \%$ & $94 \%$ & Methylation-Specific PCR & Wu et al., $2014 a$ \\
\hline & miR-34b/c & & $95 \%$ & $100 \%$ & & \\
\hline & miR-34b/c & Stool & $75 \%$ & ND & Methylation-Specific PCR & $\begin{array}{l}\text { Kalimutho et al., } \\
2011 b\end{array}$ \\
\hline & miR-34b/c & Stool & ND & ND & ND & Cho, 2011 \\
\hline & miR-148a & & & & & \\
\hline
\end{tabular}

is implicated in various malignancies, including lung adenocarcinoma, mucinous adenoma, ductal carcinoma of the pancreas, and colorectal carcinoma (Kranenburg, 2005).

Bert Vogelstein et al. were able to detect Kras gene mutations in patients with CRC, through hybridization and southern-blot assays of the isolated CFNAs. Despite a small cohort $(n=9)$, successful detection of a Kras mutation in eight of nine patients was independent of tumor type being detected in both benign and malignant neoplasms. The use of Kras mutation for detection did not depend on the tumor localization as either distal or proximal colonic tumors were detected (Sidransky et al., 1992).

This study stimulated further research to assess Kras mutation in stool. In several research studies using small cohorts $(<100)$, it was an overall concordance between tissue and stool for Kras genotype and it was possible to detect mutation even in 1000fold excess of wild-type Kras (Mixich et al., 2007). The overall results showed that Kras mutations has $34-87.5 \%$ of sensitivity for detecting CRC patients and the specificity was very high, reaching in some studies 100\% (Dong et al., 2001; Doolittle et al., 2001; Rengucci et al., 2001; Calistri et al., 2003; Chien et al., 2007; Mixich et al., 2007; Zhang et al., 2011a).

In large asymptomatic cohort, Kras mutations were found in the stool of $16.1 \%(5 / 31)$ of adenocarcinoma patients, $4.5 \%$ $(18 / 403)$ of advanced adenoma, $2.9 \%$ of patients with minor polyps (49/648), and in 1.5\% (22/1423) of subjects with negative findings on colonoscopy (Imperiale et al., 2004).

\section{APC}

APC, an Adenomatous Polyposis Coli gene, encodes a tumor suppressor protein that acts as an antagonist of the Wnt signaling pathway, thus blocks epithelial cell proliferation. It is also involved in other processes including cell migration and adhesion, apoptosis, spindle assembly, and chromosome segregation. Defects in this gene cause FAP, an autosomal dominant pre-malignant disease that usually progresses to malignancy. Disease-associated mutations tend to be clustered in a small region designated the mutation cluster region (MCR) and result in a truncated protein product (Hanson and Miller, 2005).

APC mutations were analyzed in many studies. Except for the study of Calistri et al. who found a very low frequency of APC mutations with $2 \%$ detected in the stool samples (Calistri et al., 2003), many researchers found APC mutations occurred in more than $76 \%$ of the HNPCC patients and $54 \%$ of the sporadic CRC (Koshiji et al., 2002; Traverso et al., 2002). APC mutations were also detected in patients with minor polyps, but at low fraction (2.5\%) (Imperiale et al., 2004). The specificity of APC mutations was found in more than $99 \%$ of the subjects with negative findings on colonoscopy (Koshiji et al., 2002; Traverso et al., 
2002). The combination of P53 anomalies with APC mutations increased the sensitivity of cancer detection to $96.7 \%$ (Koshiji et al., 2002).

The APC gene can carry relatively highly aberrant methylation patterns on CpG islands. In DNA from tissue samples, Azuara et al. (2010) showed the prevalence of promoter hypermethylation in tumor biopsies for APC in 20\% (50/250) of the samples tested. The analysis of 100 cases, paired normal mucosa yielded zero percentage of APC methylation.

In DNA from stool samples, the authors detected APC methylation in $37.5 \%(12 / 32)$ of patients with adenomas or carcinomas and no methylation was found in the 22 non-neoplastic subjects having either IBD or normal bowel (Azuara et al., 2010). However, when Belshaw et al. evaluated APC gene methylation in stool samples, they found no difference in methylation between the CRC patients $(n=21)$ and the healthy volunteers $(n=12)$ (Belshaw et al., 2004). The same conclusion resulted in the study of Leung et al. in the serum. They analyzed APC methylation in 49 CRC patients and 41 age-matched controls as determined with normal colonoscopy. There was no significant difference found in the concentration of methylated serum DNA between cancer patients and controls for APC gene $(p=0.21)$ (Leung et al., 2005).

\section{TP53}

The TP53 gene encodes a tumor suppressor protein containing transcriptional activation, DNA binding, and oligomerization domains. TP53 responds to diverse cellular stresses to properly regulate expression of target genes, thereby inducing cell cycle arrest, apoptosis, senescence, DNA repair, or changes in metabolism. In addition, P53 appears to induce apoptosis through non-transcriptional cytoplasmic processes. Mutations in this gene are associated with a variety of human cancers, including hereditary cancers such as Li-Fraumeni syndrome (Toledo and Wahl, 2006).

TP53 mutations were found in DNA stool samples of $25.8 \%$ $(8 / 31)$ of adenocarcinoma patients, $2.7 \%$ (11/403) of advanced adenoma, $0.8 \%(5 / 648)$ of patients with minor polyps, and in $1.1 \%(16 / 1423)$ of subjects with negative findings on colonoscopy (Imperiale et al., 2004). Higher detection rates were found in the study of Khan et al. (2000) and Dong et al. (2001). In the first study, they detected TP53 mutations in solid tumor samples of $46 \%(19 / 41)$ colorectal carcinoma patients and in peripheral blood samples of $42 \%$ (8/19) patients (Khan et al., 2000). In the study of Dong et al. the authors isolated DNA from paired stools and primary tumor samples from CRC patients. They detected TP53 mutations in the stools as well as in the tumors of $59 \%(30 / 51)$ of the CRC patients (Dong et al., 2001).

Poor performance of P53 mutations was seen in several studies. Calistri et al. (2003) analyzed TP53 exon 5-8 in the stool from 38 healthy individuals and paired stools and primary lesions from 56 CRC patients. While the detection sensitivity in the tissues was $34 \%$, the sensitivity in the stools was less than $6 \%$ (Calistri et al., 2003). Calistri et al. detected P53 mutations in the tumors of $37 \%$ $(17 / 46)$ of CRC patients and in the stool of only $6 \%(3 / 46)$ of the CRC cases (Rengucci et al., 2001).
The combination of P53 mutations with other markers increases the performance of the test to detect CRC patients. Koshiji et al. evaluated both the TP53 and APC mutations in the stool of 30 patients with sporadic CRC and 15 individuals without cancer. The combination of TP53 and APC detected the CRC patients with $97 \%$ of sensitivity and $100 \%$ of specificity (Koshiji et al., 2002).

\section{MMR GENES}

Mismatch repair genes play a key role in maintaining genomic stability, through participating in the mismatch repair pathway. The major eukaryotic MMR genes are MLH1, MLH3, MSH2, MSH3, PMS2, and MSH6 (from KEGG source record: ko03430). These genes contain microsatellites coding repeats (Fishel et al., 1993; Desai et al., 2000; Hansen et al., 2014). The deletion or insertion of one or two nucleotides in these repeats causes a frameshift mutation resulting in the production of a truncated and inactive protein that ultimately affects the MMR biological pathway (Iacopetta et al., 2010). Several other non-MMR genes were found to contain microsatellites repeats and exhibit repeats instability in CRC.

In many research studies, microsatellite instability was a rare event. Calistri et al. evaluated microsatellite instability using a set of five microsatellite markers (D2S123, D5S346, D17S250, BAT25, and BAT26) in 46 cases of CRC and 18 healthy individuals. In the healthy individuals, no genetic alterations in stool were detected. The diagnostic sensitivity of combining five microsatellites markers was 7\% in stool-DNA (Rengucci et al., 2001). Imperiale et al. used Bat-26 as microsatellite-instability marker. They found Bat-26 deletions in the stool of $6.5 \%(2 / 31)$ of adenocarcinoma patients, $1.2 \%$ (5/403) of advanced adenoma, $0.6 \%(4 / 648)$ of patients with minor polyps, and in $1.1 \%(16 / 1423)$ of subjects with negative findings on colonoscopy (Imperiale et al., 2004). Albeit the low frequency of microsatellites instability, it is important to combine microsatellites with others markers such as P53 and Kras mutations, because microsatellites instability could be present in tumors lacking P53 and Kras mutations.

\section{METHYLATION BIOMARKERS}

DNA methylation is an epigenetic mechanism that occurs in gene promoter $\mathrm{CpG}$ sites, it is a well-known mechanism for transcriptional silencing. Methylation instability events are frequently observed in CRC, resulting in the inactivation of several tumor suppressor genes or the activation of some tumor-related genes. Thereby, methylation aberration quantification can be used in diagnostics and prognosis of CRC.

Methylation in the stool. Muller et al. were the first to detect the methylation anomalies in stool DNA of CRC patients using secreted frizzled-related protein gene 2 (SFRP2). SFRP2 is a member of the SFRP family that contains a cysteine-rich domain homologous to the putative Wnt-binding site of Frizzled proteins and acts as soluble modulators of Wnt signaling pathway. As shown by many studies, the methylation of this gene is a potential marker for the presence of CRC. In the study of Muller et al., the methylation of SFRP2 was assessed in two independent sets of patients $(n=23$ and $n=26)$. SFRP2 methylation had a detection sensitivity of 90 and $77 \%$ in the training and test 
sets, respectively, and the specificity was found to be $77 \%$ (Muller et al., 2004). Similar results were found in other studies, methylated SFRP2 was found to occur in $87-94.2 \%$ of patients with CRC, $52.4-61.8 \%$ with adenomas and in $37.5-42.3 \%$ with hyperplasic polyps (Huang et al., 2007; Wang and Tang, 2008). In these studies only $5-7 \%$ revealed methylated DNA out the normal individuals tested (Huang et al., 2007; Wang and Tang, 2008). Another SFRP family member, secreted frizzled-related protein gene 1 (SFRP1) was detected methylated in the stool of CRC patients. SFRP1 methylation was found to be statistically highly significant between patients with colorectal neoplasia and the healthy group, a sensitivity of $89 \%$ and specificity of $86 \%$ for the detection of colorectal neoplasia was found for this gene (Zhang et al., 2007).

The methylation in the stool of several others markers was proposed as potential marker for CRC screening as single marker, TFPI 2 with sensitivity of $68 \%$ and specificity of $100 \%$ in the cohort of 80 patients and 30 healthy controls (Zhang et al., 2012), P16 with specificity of $20 \%$ and a specificity of $100 \%$ (Abbaszadegan et al., 2007), Fibrillin-1 with sensitivity of 72\% and specificity of 93\% (Guo et al., 2013), TFPI2 with sensitivity of $76 \%$ to $89 \%$ and a specificity of $79-93 \%$ (Glockner et al., 2009), NDRG4 in the training set yielded a sensitivity of $61 \%$, and a specificity of $93 \%$ and in an independent test set of patients the methylation of this gene yielded a sensitivity of $53 \%$ and a specificity of $100 \%$ (Melotte et al., 2009), the paraplegia-20 was found with a sensitivity and specificity of 80.2 and $100 \%$, respectively (Zhang et al., 2013a).

To increase the sensitivity for calling true positives CRC patients, researchers tried several combinations of methylation markers. In 296 fecal samples, the combination of RASSF2 and SFRP2 methylation detected $75 \%$ of patients with CRC, and $44 \%$ of patients with advanced colorectal adenomas. Only $11 \%$ of the subjects without neoplastic or active diseases were positives for at least one marker (Nagasaka et al., 2009). RARB2, p16INK4a, and MGMT methylation were combined to APC methylation. The methylation of at least one marker was detected in the stools of $75 \%(9 / 12)$ and $61.5 \%(16 / 26)$ of patients with carcinomas and $60 \%(12 / 20)$ and $40 \%(8 / 20)$ of patients with adenomas in the initial set and second set, respectively. The specificity of the combined markers on healthy subjects was 100\% (Azuara et al., 2010). The methylation of MGMT, hMLH1, and vimentin were detected, respectively, in $51.7,30.0$, and $38.3 \%$ of CRC, and in $36.5,11$, and $15.4 \%$ of colorectal adenomas, in combination the sensitivity were 75 and $59.6 \%$. The specificity of the three combined markers was $86.5 \%$ (Baek et al., 2009). The combination of the vimentin methylation to the DNA test used by Imperiale et al. (2004), improved the sensitivity of CRC detection to $80 \%$, however, the specificity was decreased (Itzkowitz et al., 2007). The diagnostic sensitivity by combining the following three markers AGTR1, WNT2, and SLT2 was 78\% (Carmona et al., 2013). The methylation frequencies of MAL, CDKN2A, and MGMT were respectively, $78.3,52.5$, and $55.1 \%$ in CRC, 58.3, 41.7 and $37.5 \%$ in colon adenomas, $26.3,15.8$ and $10.5 \%$ in hyperplastic polyps, and 3.8, 0 and $3.8 \%$ in healthy controls. However, the sensitivity of the combination those three markers was $92.8 \%$ in CRC and $70.8 \%$ in adenomas, showing significantly higher than FOBT examination (Kang et al., 2011). The combination of vimentin, OMSR, and TFPI2 methylation on stool-DNA from 107 individuals detected $86.7 \%$ of CRC and $76.5 \%$, the adenoma, the specificity was $86.7 \%$ (Zhang et al., 2011b).

Methylation abnormalities were also reported in the serum of CRC patients by many authors. Methylation abnormalities of APC, hMLH1, and HLTF were detected in the bloodstream of CRC patients. Overall, 57\% of CRC patients had methylation in at least one marker and $95 \%$ of the normal subjects were not carrying the methylation in these genes (Leung et al., 2005). A developed assay, designed to simultaneously quantify the methylation of ALX4, SEPT9, and TMEFF2, was applied to 182 peripheral blood samples from CRC patients. Methylation of ALX4, SEPT9, and TMEFF2 as single marker occurred only in 48, 75 , and $71 \%$ of the CRC patients, respectively. In combination, the sensitivity of the combined markers were improved to $81 \%$ and the specificity was $90 \%$ (He et al., 2010).

Methylation anomalies were also detected in urine from CRC patients. In a recent work, we investigated WIF1, ALX4, and vimentin methylation in either urine or serum samples of 247 patients (90 patients with neoplasia and 157 control subjects normal colonoscopy or having small adenomas less than $1 \mathrm{~cm}$ ). Hypermethylation of Wif- 1 had higher diagnostic sensitivity than Alx4 or vimentin. WIF1 methylation was observed in 26.7 and $32.6 \%$ in CRC cases $(p<0.001)$ and in $1.3 \%$ of the control patients $(p<0.001)$ in either urine or serum. Interestingly, the combination of serum and urine raised the neoplasia detection rate to $47.8 \%$ in CRC cases, compared to $2.5 \%$ in control patients (Mansour and Sobhani, 2009; Amiot et al., 2014).

\section{MicroRNA BIOMARKERS}

MicroRNAs are small non-coding RNAs that function at posttranscriptional level to regulate gene expression by binding the $3^{\prime}$-untranslated region ( $3^{\prime}$ UTR) of the target transcript (Maqbool and Hussain, 2014). MicroRNA can be aberrantly expressed or methylated in tumors and can be found and quantified either in stool or plasma. These microRNAs signatures could be a good noninvasive tool for the CRC detection (Cho, 2011; Maqbool and Hussain, 2014).

In the stool the screening of feces for 648 microRNAs showed that $39 \%$ of all these microRNAs can be detected (Kalimutho et al., 2011a). High expression levels of miR-21, miR-106a, miR-221, miR-29, miR-92, miR-34a, miR-34b/c, miR148a, and miR-144 expressions were found in the stool from patients with CRCs compared with healthy individuals (Huang et al., 2010; Link et al., 2010; Cho, 2011; Kalimutho et al., 2011 a,b; Wu et al., 2014a). Other microRNAs, such as miR-34a, miR-b/c, and miR148a were also assessed in DNA stool from CRC patients but for their methylation (Cho, 2011; Kalimutho et al., 2011b; Wu et al., 2014a). Researchers demonstrated that either the expression or the methylation of some microRNAs in the stool can be used as potential markers for CRC detection.

In the plasma, many microRNAs analyzed show variable performance for discriminating CRC from normal. In 103 CRC patients and 37 healthy normal controls, the plasma level of miR221 is shown as a potential biomarker for differentiating CRC patients from controls. At a specific cutoff value of expression, miR-221 has the sensitivity of $86 \%$ and specificity of $41 \%$ (Pu 
et al., 2010). In the study investigating 380 plasmatic microRNAs, miR-21 was found to differentiate CRC patients from controls with $90 \%$ of sensitivity and specificity (Kanaan et al., 2012). In the analysis of 196 plasma samples from 123 patients newly diagnosed with sporadic colorectal neoplasia, miR-18a, miR-19a, miR-19b, miR-15b, miR-29a, and miR-335 were significantly up-regulated in CRC patients (Giraldez et al., 2013). They differentiate patients with CRC from controls with area under curve (AUC) values ranging from 0.80 (95\% confidence interval [CI], 0.71-0.89) to 0.70 (95\% CI, 0.59-0.80). In this study the only marker for advanced adenomas (AAs) was miR-18a that was significantly upregulated in AAs compared with controls; the AUC value was 0.64 (95\% CI, 0.52-0.75) (Giraldez et al., 2013). The investigation of 380 plasmatic microRNAs, in a small cohort of patients, revealed a panel of eight microRNAs (miR-532-3p, miR-331, miR-195, miR-17, miR-142-3p, miR-15b, miR-532, and miR-652) that was found to distinguish polyps from controls with high accuracy $[(\mathrm{AUC})=0.868$ (95\% [CI]: 0.76-0.98)] (Kanaan et al., 2013). In several others studies, others microRNA, were found also in the plasma of CRC patients as promising markers, such as, let-7g, miR-31, miR-181b, miR-203, miR-135b, RNU2-1f, let-7a, miR1229, miR-1246, miR-150, miR-223, and miR-23a (Ng et al., 2009; Huang et al., 2010; Pu et al., 2010; Cheng et al., 2011; Kalimutho et al., 2011a; Kanaan et al., 2012, 2013; Wang et al., 2012, 2014; Baraniskin et al., 2013; Giraldez et al., 2013; Luo et al., 2013; Zhang et al., 2013b; Komatsu et al., 2014; Ogata-Kawata et al., 2014; Wu et al., 2014b; Zanutto et al., 2014).

\section{CFNA MARKERS TRANSLATION FROM RESEARCH TO CLINICAL USE}

The biomarkers described to this point promise to be an excellent way of detecting CRC, in the average-risk population. This population typically includes individuals who are more than 50 years old or are first-degree relatives of CRC-affected patients or patients with inflammatory bowel disease (IBD) possibly having previously undetectable mucosal alterations, a prior step to detectable premalignant neoplastic lesions. We summarize in the following the advantages of CFNA based CRC detection.

Genetic anomalies: (1) appear in a large fraction of sporadic non-hereditary tumors, (2) they appear in early stage during gut cells transition to tumors, (3) they are well defined and described, (4) a large number of cells carrying these anomalies are shed from the developing tumor and could be found in biological effluents, in particular stool, serum, and urine, (5) the genetic anomalies can be easily identified by simple, quick, and relatively inexpensive molecular approaches.

These noninvasive molecular approaches (1) show high sensitivity and specificity in tumor detection and staging, (2) a higher performance than the FOBT or FIT results, and (3) can be used both as prognostic factor to monitor the disease progression and therapy responsiveness, by expanding or refining the biomarker panel as our tumor-biology knowledge increases and evolves.

There are multiple screening approaches that were endorsed by the American Cancer Society (ACS) including stool or serum DNA testing, and several companies are currently developing tests based on these approaches. Nevertheless, studies published to date that focus on the biomarker validation in large and long-term randomized trials are rare and implementation in screening trials have not been seen. For such validation and implementation, some technical challenges could be encountered,

a. The DNA present in biological effluents could be a limiting factor for the less sensitive molecular tools as the quantity of CFNA extracted varies; stool contains higher DNA quantity compared to serum and urine. From stool we can reproducibly get a few $\mu \mathrm{g}$ of DNA per $100 \mathrm{mg}$ of stool; however, human DNA represents merely $0.01 \%$ of the total stool DNA. The urine seems to carry the lowest quantity of DNA, typically only a few ng per $\mathrm{ml}$ of urine.

b. The origin of circulating free DNA in body fluids is not yet well established. While the cell-free DNA found in CRC patients may come from highly proliferative neoplastic colonic cells, a normal cell (colonic cells or immune cells) origin has also been indicated. Normal cells have been also found to ubiquitously release DNA fragments (Stroun et al., 2000; van der Vaart and Pretorius, 2007). The presence of different nontumor DNA sources may obscure the tumor DNA and make genetic biomarker detection difficult. Indeed, the quantity of circulating tumor nucleic acids found in body fluids of cancer patients may be very low and varies considerably.

In plasma, Leary et al. showed that tumor DNA of cancer patients ranges from 1.4 to $47.9 \%$ of wild-type (Leary et al., 2012). Mouliere et al. showed that the quantity of mutant DNA in plasma can be found even higher than what were previously described showing a variation range from 0.13 to $68 \%$ in samples from mutation-positives CRC patients (Mouliere et al., 2013). This variation can be influenced by cancer staging, where advanced stages carry more cell free DNA than early stages, as was shown by Bert Vogelstein et al. who quantified the tumoral DNA extracted from plasma of CRC patients and reported that the means of mutated DNA found were $0.02,0.04,0.94$, and $11.05 \%$ for adenomas, stage A, stage B, and stage $\mathrm{D}$, respectively. The lowest quantity of mutant fragment that was seen is $0.001 \%$. While the quantity of mutant fragment appears to correlate positively with the staging, the lowest quantity was not specific to any stage (Diehl et al., 2005).

In stool, Sidransky et al. (1992) showed that the tumor mutated DNA represent a low rate, $4-8 \%$ the wild-type DNA of CRC patients. Thus, both in plasma and in stool, the high sensitivity of the molecular approach is needed to detect patients with presumably curable CRC.

c. The quality of extracted CFNA can vary considerably since body fluids do not preserve cell-free nucleic acid integrity. Stabilization of the body fluids just after the collection is strongly recommended, especially for stool samples.

d. Some body fluids can carry some inhibitors, such as food digestion products, bacterial contaminants, and nucleic acids released from others cells, that can reduce the CRC detection performance.

e. The cell free nucleic acids found in blood, urine, and stool are in general fragmented DNA, less than $200 \mathrm{bp}$. Then, the evaluation of the size of extracted CFNA and targeting shorter 
regions should be considered to attain high performance of detection.

f. High-Throughput Sequencing is a good tool that enables screening the whole CFNA. High diagnostic value could be achieved by using pair-end libraries and deep sequencing coverage. However, the sequencing cost is still too high to be implemented in routine as screening approach.

\section{CONCLUSION}

Research studies have shown that many genetic markers were promising for CRC screening and diagnosis. A long term-clinical trial evaluating all these biomarkers in the same cohort and comparing stool, serum and urine is needed to select the best composite panel. In addition, the challenges encountered with nucleic acids extracted from body fluids need to be overcome to identify the standard protocol and the robust tool to implement these biomarkers as standard test for CRC screening, diagnosis, and prognosis.

\section{ACKNOWLEDGMENTS}

I would like to thank Dr. Roberto Incitti and Dr. Anthony Robertson for their constructive criticism and comments to this present review. I would like also to thank Mr. Sami M. Bashir and Technology Transfer and Innovation at KAUST for their help. I apologize if we missed any published work related to this topic.

\section{REFERENCES}

Abbaszadegan, M. R., Tavasoli, A., Velayati, A., Sima, H. R., Vosooghinia, H., Farzadnia, M., et al. (2007). Stool-based DNA testing, a new noninvasive method for colorectal cancer screening, the first report from Iran. World J. Gastroenterol. 13, 10528-10533.

Amiot, A., Mansour, H., Baumgaertner, I., Delchier, J. C., Tournigand, C., Furet, J. P., et al. (2014). The detection of the methylated wif-1 gene is more accurate than a fecal occult blood test for colorectal cancer screening. PLoS ONE 9:e99233. doi: 10.1371/journal.pone.0099233

Azuara, D., Rodriguez-Moranta, F., de Oca, J., Soriano-Izquierdo, A., Mora, J., Guardiola, J., et al. (2010). Novel methylation panel for the early detection of colorectal tumors in stool DNA. Clin. Colorectal Cancer 9, 168-176. doi: 10.3816/CCC.2010.n.023

Baek, Y. H., Chang, E., Kim, Y. J., Kim, B. K., Sohn, J. H., and Park, D. I. (2009). Stool methylation-specific polymerase chain reaction assay for the detection of colorectal neoplasia in Korean patients. Dis. Colon Rectum. 52, 8452-8459. discussion: 9-63. doi: 10.1007/DCR.0b013e3181a79533

Baraniskin, A., Nopel-Dunnebacke, S., Ahrens, M., Jensen, S. G., Zollner, H., Maghnouj, A., et al. (2013). Circulating U2 small nuclear RNA fragments as a novel diagnostic biomarker for pancreatic and colorectal adenocarcinoma. Int. J. Cancer 132, E48-E57. doi: 10.1002/ijc.27791

Belshaw, N. J., Elliott, G. O., Williams, E. A., Bradburn, D. M., Mills, S. J., Mathers, J. C., et al. (2004). Use of DNA from human stools to detect aberrant CpG island methylation of genes implicated in colorectal cancer. Cancer Epidemiol. Biomarkers Prev. 13, 9495-9501.

Berger, B. M., Robison, L., and Glickman, J. (2003). Colon cancer-associated DNA mutations: marker selection for the detection of proximal colon cancer. Diagn. Mol. Pathol. 12, 487-492. doi: 10.1097/00019606-20031200000002

Bin Raies, A., Mansour, H., Incitti, R., and Bajic, V. B. (2013). Combining position weight matrices and document-term matrix for efficient extraction of associations of methylated genes and diseases from free text. PLOS ONE 8:e77848. doi: 10.1371/journal.pone.0077848

Borchers, R., Heinzlmann, M., Zahn, R., Witter, K., Martin, K., Loeschke, K., et al. (2002). K-ras mutations in sera of patients with colorectal neoplasias and longstanding inflammatory bowel disease. Scand. J. Gastroenterol. 37, 615-618. doi: $10.1080 / 00365520212505$
Boyle, P., and Langman, J. S. (2000). ABC of colorectal cancer: epidemiology. BMJ 321, 726405-726408. doi: 10.1136/bmj.321.7264.805

Calistri, D., Rengucci, C., Bocchini, R., Saragoni, L., Zoli, W., and Amadori, D. (2003). Fecal multiple molecular tests to detect colorectal cancer in stool. Clin. Gastroenterol. Hepatol. 1, 577-583. doi: 10.1053/S1542-3565(03)00186-1

Carmona, F. J., Azuara, D., Berenguer-Llergo, A., Fernandez, A. F., Biondo, S., de Oca, J., et al. (2013). DNA methylation biomarkers for noninvasive diagnosis of colorectal cancer. Cancer Prev. Res. 6, 756-765. doi: 10.1158/1940-6207.CAPR12-0501

Chen, Y., Chen, G., Feng, S., Pan, J., Zheng, X., Su, Y., et al. (2012). Label-free serum ribonucleic acid analysis for colorectal cancer detection by surface-enhanced Raman spectroscopy and multivariate analysis. J. Biomed. Opt. 17:667003. doi: 10.1117/1.JBO.17.6.067003

Cheng, H., Zhang, L., Cogdell, D. E., Zheng, H., Schetter, A. J., Nykter, M., et al. (2011). Circulating plasma MiR-141 is a novel biomarker for metastatic colon cancer and predicts poor prognosis. PLOS ONE 6:e17745. doi: 10.1371/journal.pone. 0017745

Chien, C. C., Chen, S. H., Liu, C. C., Lee, C. L., Yang, R. N., Yang, S. H., et al. (2007). Correlation of K-ras codon 12 mutations in human feces and ages of patients with colorectal cancer (CRC). Transl. Res. 149, 26-102. doi: 10.1016/j.trsl.2006.09.006

Cho, W. C. (2011). Epigenetic alteration of microRNAs in feces of colorectal cancer and its clinical significance. Expert Rev. Mol. Diagn. 11, 791-794. doi: 10.1586/erm.11.57

Davidson, L. A., Jiang, Y. H., Derr, J. N., Aukema, H. M., Lupton, J. R., and Chapkin, R. S. (1994). Protein kinase C isoforms in human and rat colonic mucosa. Arch. Biochem. Biophys. 312, 247-253. doi: 10.1006/abbi.1994.1344

Deng, L., Qi, Z., Zou, B., Wu, H., Huang, H., Kajiyama, T., et al. (2012). Digital detection of multiple minority mutants in stool DNA for noninvasive colorectal cancer diagnosis. Anal. Chem. 84, 13645-13652. doi: 10.1021/ac3008016

Desai, D. C., Lockman, J. C., Chadwick, R. B., Gao, X., Percesepe, A., Evans, D. G. R., et al. (2000). Recurrent germline mutation in MSH2 arises frequently de novo. J. Med. Genet. 37, 946-952. doi: 10.1136/jmg.37.9.646

Diehl, F., Li, M., Dressman, D., He, Y., Shen, D., Szabo, S., et al. (2005). Detection and quantification of mutations in the plasma of patients with colorectal tumors. Proc. Natl. Acad. Sci. U.S.A. 102, 456368-456373. doi: 10.1073/pnas.0507904102

Dong, S. M., Traverso, G., Johnson, C., Geng, L., Favis, R., Boynton, K., et al. (2001). Detecting colorectal cancer in stool with the use of multiple genetic targets. J. Natl. Cancer Inst. 93, 1158-1165. doi: 10.1093/jnci/93.11.858

Doolittle, B. R., Emanuel, J., Tuttle, C., and Costa, J. (2001). Detection of the mutated K-Ras biomarker in colorectal carcinoma. Exp. Mol. Pathol. 70, 389-301. doi: 10.1006/exmp.2001.2364

Ebert, M. P., Model, F., Mooney, S., Hale, K., Lograsso, J., Tonnes-Priddy, L., et al. (2006). Aristaless-like homeobox-4 gene methylation is a potential marker for colorectal adenocarcinomas. Gastroenterology 131, 5418-5430. doi: 10.1053/j.gastro.2006.08.034

Ferlay, J., Shin, H. R., Bray, F., Forman, D., Mathers, C., and Parkin, D. M., (2010). Estimates of worldwide burden of cancer in 2008: GLOBOCAN 2008. Int. J. Cancer 127, 12893-12917. doi: 10.1002/ijc.25516

Fishel, R., Lescoe, M. K., Rao, M. R., Copeland, N. G., Jenkins, N. A., Garber, J., et al. (1993). The human mutator gene homolog MSH2 and its association with hereditary nonpolyposis colon cancer. Cell 75, 5027-5038. doi: 10.1016/00928674(93)90546-3

Gerecke, C., Mascher, C., Gottschalk, U., Kleuser, B., and Scholtka, B. (2013). Ultrasensitive detection of unknown colon cancer-initiating mutations using the example of the Adenomatous polyposis coli gene. Cancer Prev. Res. 6, 998-907. doi: 10.1158/1940-6207.CAPR-13-0145

Giraldez, M. D., Lozano, J. J., Ramirez, G., Hijona, E., Bujanda, L., Castells, A., et al. (2013). Circulating microRNAs as biomarkers of colorectal cancer: results from a genome-wide profiling and validation study. Clin. Gastroenterol. Hepatol. 11, 681-8 e3. doi: 10.1016/j.cgh.2012.12.009

Glockner, S. C., Dhir, M., Yi, J. M., McGarvey, K. E., Van Neste, L., Louwagie, J., et al. (2009). Methylation of TFPI2 in stool DNA: a potential novel biomarker for the detection of colorectal cancer. Cancer Res. 69, 11691-11699. doi: 10.1158/0008-5472.CAN-08-0142

Guo, Q., Song, Y., Zhang, H., Wu, X., Xia, P., and Dang, C. (2013). Detection of hypermethylated fibrillin-1 in the stool samples of colorectal cancer patients. Med. Oncology. 30, 495. doi: 10.1007/s12032-013-0695-4 
Haggar, F. A., and Boushey, R. P. (2009). Colorectal cancer epidemiology: incidence, mortality, survival, and risk factors. Clin. Colon Rectal Surg. 22, 491-497. doi: $10.1055 / \mathrm{s}-0029-1242458$

Hansen, M. F., Neckmann, U., Lavik, L. A., Vold, T., Gilde, B., Toft, R. K., et al. (2014). A massive parallel sequencing workflow for diagnostic genetic testing of mismatch repair genes. Mol Genet Genomic Med. 2, 286-200. doi: $10.1002 / \mathrm{mgg} 3.62$

Hanson, C. A., and Miller, J. R. (2005). Non-traditional roles for the Adenomatous Polyposis Coli (APC) tumor suppressor protein. Gene 361, 1-12. doi: 10.1016/j.gene.2005.07.024

Hasegawa, Y., Takeda, S., Ichii, S., Koizumi, K., Maruyama, M., Fujii, A., et al. (1995). Detection of K-ras mutations in DNAs isolated from feces of patients with colorectal tumors by mutant-allele-specific amplification (MASA). Oncogene 10, 7441-7445.

He, Q., Chen, H. Y., Bai, E. Q., Luo, Y. X., Fu, R. J., He, Y. S., et al. (2010). Development of a multiplex MethyLight assay for the detection of multigene methylation in human colorectal cancer. Cancer Genetics Cytogenet. 202, 1-10. doi: 10.1016/j.cancergencyto.2010.05.018

Hellebrekers, D. M., Lentjes, M. H., van den Bosch, S. M., Melotte, V., Wouters, K. A., Daenen, K. L., et al. (2009). GATA4 and GATA5 are potential tumor suppressors and biomarkers in colorectal cancer. Clin. Cancer Res. 15, 12990-12997. doi: 10.1158/1078-0432.CCR-09-0055

Huang, Z., Huang, D., Ni, S., Peng, Z., Sheng, W., and Du, X. (2010). Plasma microRNAs are promising novel biomarkers for early detection of colorectal cancer. Int. J. Cancer 127, 118-126. doi: 10.1002/ijc.25007

Huang, Z., Li, L., and Wang, J. (2007). Hypermethylation of SFRP2 as a potential marker for stool-based detection of colorectal cancer and precancerous lesions. Dig. Dis. Sci. 52, 9287-9291. doi: 10.1007/s10620-007-9755-y

Iacopetta, B., Grieu, F., and Amanuel, B. (2010). Microsatellite instability in colorectal cancer. Asia Pac. J. Clin. Oncol. 6, 460-469. doi: 10.1111/j.17437563.2010.01335.x

Imperiale, T. F., Ransohoff, D. F., Itzkowitz, S. H., Levin, T. R., Lavin, P., Lidgard, G. P., et al. (2014). Multitarget stool DNA testing for colorectal-cancer screening. N. Engl. J. Med. 370, 14287-14297. doi: 10.1056/NEJMoa1311194

Imperiale, T. F., Ransohoff, D. F., Itzkowitz, S. H., Turnbull, B. A., Ross, M. E., and Colorectal Cancer Study, G. (2004). Fecal DNA versus fecal occult blood for colorectal-cancer screening in an average-risk population. N. Engl. J. Med. 351, 26704-26714. doi: 10.1056/NEJMoa033403

Itzkowitz, S. H., Jandorf, L., Brand, R., Rabeneck, L., Schroy, P. C. 3rd, Sontag, S., et al. (2007). Improved fecal DNA test for colorectal cancer screening. Clin. Gastroenterol. Hepatol. 5, 111-117. doi: 10.1016/j.cgh.2006.10.006

Kalimutho, M., Del Vecchio Blanco, G., Di Cecilia, S., Sileri, P., Cretella, M., Pallone, F., et al. (2011a). Differential expression of miR-144* as a novel fecal-based diagnostic marker for colorectal cancer. J. Gastroenterol. 46, 12391-12402. doi: 10.1007/s00535-011-0456-0

Kalimutho, M., Di Cecilia, S., Del Vecchio Blanco, G., Roviello, F., Sileri, P., Cretella, M., et al. (2011b). Epigenetically silenced miR-34b/c as a novel faecal-based screening marker for colorectal cancer. Br. J. Cancer. 104, 11770-11778. doi: $10.1038 /$ bjc. 2011.82

Kanaan, Z., Rai, S. N., Eichenberger, M. R., Roberts, H., Keskey, B., Pan, J., et al. (2012). Plasma miR-21: a potential diagnostic marker of colorectal cancer. Ann. Surg. 256, 344-351. doi: 10.1097/SLA.0b013e31826 $5 \mathrm{bd} 6 \mathrm{f}$

Kanaan, Z., Roberts, H., Eichenberger, M. R., Billeter, A., Ocheretner, G., Pan, J., et al. (2013). A plasma microRNA panel for detection of colorectal adenomas: a step toward more precise screening for colorectal cancer. Ann. Surg. 258, 300-308. doi: 10.1097/SLA.0b013e3182a15bcc

Kang, Y. P., Cao, F. A., Chang, W. J., Lou, Z., Wang, H., Wu, L. L., et al. (2011). [Gene methylation in stool for the screening of colorectal cancer and pre-malignant lesions]. Zhonghua Wei Chang Wai Ke Za Zhi 14, 12-16.

Khan, Z. A., Jonas, S. K., Le-Marer, N., Patel, H., Wharton, R. Q., Tarragona, A., et al. (2000). P53 mutations in primary and metastatic tumors and circulating tumor cells from colorectal carcinoma patients. Clin. Cancer Res. 6, 9499-9504.

Komatsu, S., Ichikawa, D., Takeshita, H., Morimura, R., Hirajima, S., Tsujiura, M., et al. (2014). Circulating miR-18a: a sensitive cancer screening biomarker in human cancer. In Vivo 28, 393-397.

Koshiji, M., Yonekura, Y., Saito, T., and Yoshioka, K. (2002). Microsatellite analysis of fecal DNA for colorectal cancer detection. J. Surg. Oncol. 80, 14-40. doi: $10.1002 /$ jso. 10096
Kranenburg, O. (2005). The KRAS oncogene: past, present, and future. Biochim. Biophys. Acta. 1756, 21-22. doi: 10.1016/j.bbcan.2005.10.001

Leary, R. J., Sausen, M., Kinde, I., Papadopoulos, N., Carpten, J. D., Craig, D., et al. (2012). Detection of chromosomal alterations in the circulation of cancer patients with whole-genome sequencing. Sci. Transl. Med. 4:16262ra54. doi: 10.1126/scitranslmed.3004742

Leung, W. K., To, K. F., Man, E. P., Chan, M. W., Bai, A. H., Hui, A. J., et al. (2005). Quantitative detection of promoter hypermethylation in multiple genes in the serum of patients with colorectal cancer. Am. J. Gastroenterol. 100, 10274-10279. doi: 10.1111/j.1572-0241.2005.50412.x

Link, A., Balaguer, F., Shen, Y., Nagasaka, T., Lozano, J. J., Boland, C. R., et al. (2010). Fecal MicroRNAs as novel biomarkers for colon cancer screening. Cancer Epidemiol. Biomarkers Prev. 19, 7766-7774. doi: 10.1158/1055-9965.EPI10-0027

Lledo, S. M., Garcia-Granero, E., Dasi, F., Ripoli, R., Garcia, S. A., Cervantes, A., et al. (2004). Real time quantification in plasma of human telomerase reverse transcriptase (hTERT) mRNA in patients with colorectal cancer. Colorectal Dis. 6, 436-442. doi: 10.1111/j.1463-1318.2004.00627.x

Luo, X., Stock, C., Burwinkel, B., and Brenner, H. (2013). Identification and evaluation of plasma microRNAs for early detection of colorectal cancer. PLoS ONE 8:e62880. doi: 10.1371/journal.pone.0062880

Mandel, P., and Metais, P. (1948). Les acides nucléiques du plasma sanguin chezl'homme. C. R. Seances Soc. Biol. Fil. 142, 241-243.

Mansour, H., Incitti, R., and Bajic, V. (2013). Composite Biomarker for Non-Invasive Screening, Diagnosis and Prognosis of Colorectal Cancer. Paris: World Intellectual Property Organization (WIPO).

Mansour, H., and Sobhani, I. (2009). Method, Process, and Kit for Diagnosis or Prognosis of Colorectal Cancer. Paris: Wold Intellectual Property Organization (WIPO).

Maqbool, R., and Hussain, M. U. (2014). MicroRNAs and human diseases: diagnostic and therapeutic potential. Cell Tissue Res. doi: 10.1007/s00441-013-1787-3. [Epub ahead of print].

Melotte, V., Lentjes, M. H., van den Bosch, S. M., Hellebrekers, D. M., de Hoon, J. P., Wouters, K. A., et al. (2009). N-Myc downstream-regulated gene 4 (NDRG4): a candidate tumor suppressor gene and potential biomarker for colorectal cancer. J. Natl. Cancer Inst. 101, 1316-1327. doi: 10.1093/jnci/djp131

Mixich, F., Ioana, M., Voinea, F., Saftoiu, A., and Ciurea, T. (2007). Noninvasive detection through REMS-PCR technique of K-ras mutations in stool DNA of patients with colorectal cancer. J. Gastrointestin. Liver Dis. 16, $1-10$.

Mouliere, F., El Messaoudi, S., Gongora, C., Guedj, A. S., Robert, B., Del Rio, M., et al. (2013). Circulating Cell-Free DNA from Colorectal Cancer Patients May Reveal High KRAS or BRAF Mutation Load. Transl. Oncol. 6, 319-328. doi: $10.1593 /$ tlo. 12445

Muller, H. M., Oberwalder, M., Fiegl, H., Morandell, M., Goebel, G., Zitt, M., et al. (2004). Methylation changes in faecal DNA: a marker for colorectal cancer screening? Lancet 363, 9417283-9417285. doi: 10.1016/S0140-6736(04) 16002-9

Nagasaka, T., Tanaka, N., Cullings, H. M., Sun, D. S., Sasamoto, H., Uchida, T., et al. (2009). Analysis of fecal DNA methylation to detect gastrointestinal neoplasia. J. Natl. Cancer Inst. 101, 18244-18258. doi: 10.1093/inci/djp265

Ng, E. K., Chong, W. W., Jin, H., Lam, E. K., Shin, V. Y., Yu, J., et al. (2009) Differential expression of microRNAs in plasma of patients with colorectal cancer: a potential marker for colorectal cancer screening. Gut 58, 10375-10381. doi: 10.1136/gut.2008.167817

Ogata-Kawata, H., Izumiya, M., Kurioka, D., Honma, Y., Yamada, Y., Furuta, K., et al. (2014). Circulating exosomal microRNAs as biomarkers of colon cancer. PLoS ONE 9:e92921. doi: 10.1371/journal.pone.0092921

Pu, X. X., Huang, G. L., Guo, H. Q., Guo, C. C., Li, H., Ye, S., et al. (2010). Circulating miR-221 directly amplified from plasma is a potential diagnostic and prognostic marker of colorectal cancer and is correlated with p53 expression. J. Gastroenterol. Hepatol. 25, 10674-10680. doi: 10.1111/j.14401746.2010.06417.x

Ratto, C., Flamini, G., Sofo, L., Nucera, P., Ippoliti, M., Curigliano, G., et al. (1996). Detection of oncogene mutation from neoplastic colonic cells exfoliated in feces. Dis. Colon Rectum. 39, 11238-11244. doi: 10.1007/BF02055116

Rengucci, C., Maiolo, P., Saragoni, L., Zoli, W., Amadori, D., and Calistri, D. (2001). Multiple detection of genetic alterations in tumors and stool. Clin. Cancer Res. 7, 390-393. 
Roperch, J. P., Incitti, R., Forbin, S., Bard, F., Mansour, H., Mesli, F., et al. (2013). Aberrant methylation of NPY, PENK, and WIF1 as a promising marker for blood-based diagnosis of colorectal cancer. BMC Cancer 13:566. doi: 10.1186/1471-2407-13-566

Scholefield, J. H., Moss, S. M., Mangham, C. M., Whynes, D. K., and Hardcastle, J. D. (2012). Nottingham trial of faecal occult blood testing for colorectal cancer: a 20-year follow-up. Gut 61, 7036-7040. doi: 10.1136/gutjnl-2011300774

Schweiger, M. R., Hussong, M., Rohr, C., and Lehrach, H. (2013). Genomics and epigenomics of colorectal cancer. Wiley Interdiscip. Rev. Syst. Biol. Med. 5, 205-219. doi: 10.1002/wsbm.1206

Shaukat, A., Mongin, S. J., Geisser, M. S., Lederle, F. A., Bond, J. H., Mandel, J. S., et al. (2013). Long-term mortality after screening for colorectal cancer. N. Engl. J. Med. 369, 12106-12114. doi: 10.1056/NEJMoa1300720

Sidransky, D., Tokino, T., Hamilton, S. R., Kinzler, K. W., Levin, B., Frost, P., et al. (1992). Identification of ras oncogene mutations in the stool of patients with curable colorectal tumors. Science 256, 505302-505305. doi: 10.1126/science. 1566048

Stroun, M., Maurice, P., Vasioukhin, V., Lyautey, J., Lederrey, C., Lefort, F., et al. (2000). The origin and mechanism of circulating DNa. Ann. N.Y. Acad. Sci. 906, 161-168. doi: 10.1111/j.1749-6632.2000.tb06608.x

Toledo, F., and Wahl, G. M. (2006). Regulating the p53 pathway: in vitro hypotheses, in vivo veritas. Nat. Rev. Cancer 6, 1209-1223. doi: 10.1038/nrc2012

Traverso, G., Shuber, A., Levin, B., Johnson, C., Olsson, L., Schoetz, D. J. Jr., et al. (2002). Detection of APC mutations in fecal DNA from patients with colorectal tumors. N. Engl. J. Med. 346, 511-520. doi: 10.1056/NEJMoa 012294

van der Vaart, M., and Pretorius, P. J. (2007). The origin of circulating free DNa. Clin. Chem. 53, 12215. doi: 10.1373/clinchem.2007.092734

Villa, E., Dugani, A., Rebecchi, A. M., Vignoli, A., Grottola, A., Buttafoco, P., et al. (1996). Identification of subjects at risk for colorectal carcinoma through a test based on K-ras determination in the stool. Gastroenterology 110, 5346-5353. doi: 10.1053/gast.1996.v110.pm8613038

Wang, D. R., and Tang, D. (2008). Hypermethylated SFRP2 gene in fecal DNA is a high potential biomarker for colorectal cancer noninvasive screening. World $J$. Gastroenterol. 14, 424-431.

Wang, J., Huang, S. K., Zhao, M., Yang, M., Zhong, J. L., Gu, Y. Y., et al. (2014). Identification of a circulating microRNA signature for colorectal cancer detection. PLoS ONE 9:e87451. doi: 10.1371/journal.pone.0087451

Wang, Q., Huang, Z., Ni, S., Xiao, X., Xu, Q., Wang, L., et al. (2012). Plasma miR601 and miR-760 are novel biomarkers for the early detection of colorectal cancer. PLoS ONE 7:e44398. doi: 10.1371/journal.pone.0044398

Wu, C. W., Ng, S. C., Dong, Y., Tian, L., Ng, S. S., Leung, W. W., et al. (2014b). Identification of microRNA-135b in stool as a potential noninvasive biomarker for colorectal cancer and adenoma. Clin. Cancer Res. 20, 11994-13002. doi: 10.1158/1078-0432.CCR-13-1750

Wu, X. D., Song, Y. C., Cao, P. L., Zhang, H., Guo, Q., Yan, R., et al. (2014a). Detection of miR-34a and $\mathrm{miR}-34 \mathrm{~b} / \mathrm{c}$ in stool sample as potential screening biomarkers for noninvasive diagnosis of colorectal cancer. Med. Oncol. 31, 494. doi: 10.1007/s12032-014-0894-7

Yamao, T., Matsumura, Y., Shimada, Y., Moriya, Y., Sugihara, K., Akasu, T., et al. (1998). Abnormal expression of CD44 variants in the exfoliated cells in the feces of patients with colorectal cancer. Gastroenterology 114, 6196-6205. doi: 10.1016/S0016-5085(98)70425-1

Zanutto, S., Pizzamiglio, S., Ghilotti, M., Bertan, C., Ravagnani, F., Perrone, F., et al. (2014). Circulating miR-378 in plasma: a reliable, haemolysisindependent biomarker for colorectal cancer. Br. J. Cancer. 110, 4001-4007. doi: 10.1038/bjc.2013.819

Zhang, G. J., Zhou, T., Liu, Z. L., Tian, H. P., and Xia, S. S. (2013b). Plasma miR-200c and miR-18a as potential biomarkers for the detection of colorectal carcinoma. Mol. Clin. Oncol. 1, 279-284. doi: 10.3892/mco.2013.61

Zhang, H., Song, Y. C., and Dang, C. X. (2013a). Detection of hypermethylated spastic paraplegia-20 in stool samples of patients with colorectal cancer. Int. J. Med. Sci. 10, 330-334. doi: 10.7150/ijms.5278

Zhang, H., Wang, X., Ma, Q., Zhou, Z., and Fang, J. (2011a). Rapid detection of low-abundance K-ras mutation in stools of colorectal cancer patients using chip-based temperature gradient capillary electrophoresis. Lab. Invest. 91, 588-598. doi: 10.1038/labinvest.2010.200

Zhang, J., Yang, S., Xie, Y., Chen, X., Zhao, Y., He, D., et al. (2012). Detection of methylated tissue factor pathway inhibitor 2 and human long DNA in fecal samples of patients with colorectal cancer in China. Cancer Epidemiol. 36, 13-17. doi: 10.1016/j.canep.2011.04.006

Zhang, J. P., Wang, J., Gui, Y. L., Zhu, Q. Q., Xu, Z. W., and Li, J. S. (2011b). [Human stool vimentin, oncostatin $\mathrm{M}$ receptor and tissue factor pathway inhibitor 2 gene methylation analysis for the detection of colorectal neoplasms]. Zhonghua Yi Xue Za Zhi 91, 35482-35484.

Zhang, W., Bauer, M., Croner, R. S., Pelz, J. O., Lodygin, D., Hermeking, H., et al. (2007). DNA stool test for colorectal cancer: hypermethylation of the secreted frizzled-related protein-1 gene. Dis. Colon Rectum 50, 10618-10626. discussion: 26-27. doi: 10.1007/s10350-007-0286-6

Conflict of Interest Statement: The author declares that the research was conducted in the absence of any commercial or financial relationships that could be construed as a potential conflict of interest.

Received: 04 April 2014; accepted: 29 May 2014; published online: 27 August 2014. Citation: Mansour H (2014) Cell-free nucleic acids as noninvasive biomarkers for colorectal cancer detection. Front. Genet. 5:182. doi: 10.3389/fgene.2014.00182 This article was submitted to Genomic Assay Technology, a section of the journal Frontiers in Genetics.

Copyright (C) 2014 Mansour. This is an open-access article distributed under the terms of the Creative Commons Attribution License (CC BY). The use, distribution or reproduction in other forums is permitted, provided the original author(s) or licensor are credited and that the original publication in this journal is cited, in accordance with accepted academic practice. No use, distribution or reproduction is permitted which does not comply with these terms. 